УАK 316.356 .2

ББК 60.561 .5

DOI 10.22394/1682-2358-2019-4-73-81

Z.S. Elsaeva, post-graduate student of the Sociology and Social Policy Department, Povolzhsky Institute of Management named after P.A. Stolypin, Branch of the Russian Presidential Academy of National Economy and Public Administration

\section{DESIGNING MALE ROLES IN POLYETHNIC FAMILY MODELS}

The situation of family crisis in modern Russia is considered. The logic of changing family relations models is interpreted in the paradigm of the dialogue of cultures, based on the comparison of the established practices in Russian Federation with the Islamic tradition. The risks arising from the spread of the attitude towards interethnic marriages among Russian women are specified.

Key words and word-combinations: traditional family model, patriarchal family, gender roles, cultural identity, dialogue of cultures, cultures of everyday life.
3.С. ЭльсаеЊа, аспирант кафедри соииологии и сочиальной политики Поволжского института управления имени П.А.Стольппина - филиала Российской академии народного хозяйства и государственной службы при Президенте РФ (email: elsaeva.zarema@mail.ru)

\section{КОНСТРУИРОВАНИЕ МУЖСКИХ РОАЕЙ B MOАE $\Lambda Я X$ ПОАИЭТНИЧНЫХ СЕМЕЙ}

Аннотащия. Рассматривается ситуация кризиса семьи в современной России. Осмысление логики смены моделей семейных отношений ведется в парадигме диалога культур, на основе сопоставления сложившихся в Российской Федерации практик с исламской традицией. Артикулируются риски, порождаемые распространением установки на межнациональные браки среди российских женщин.

Ключевые слова и словосочетания: традиционная модель семьи, патриархальная семья, гендерные роли, культурная идентичность, диалог культур, культуры повседневности.

C временная ситуация семейно-брачных отношений в России, как и в Аругих странах, прошеАших стадию индустриального развития, в науке и пубцицистике рассматривается как кризисная $[1 ; 2]$. Описание этого кризиса сводится прежде всего к процессу делегитимизаџии в общественном мнении традиџионной модели семьи.

В патриархальной семье власть ее главы представляется абсолютной, но в действи- 
тельности она жестко регламентирована традицией [3]. Мужчина может, разумеется, игнорировать интенџии Аомочадџев (в глазах представителей его социокуиьтурной среды он несет ответственность за их нетрадиционные потребности и желания), но отнюдь не свободен в выборе стратегий поведения. Имушество рода положено сохранять и приумножать, жен и детей кормить и одевать ( ииш в общепризнанных форс-мажкорных обстоятельствах их выживанием можно пренебречь). Между тем в современных рыночных экономиках гарантий такого положения вещей у главы семейства нет. Именно отсюда, а не из «развращенности нравов» начинается размывание его власти.

ОАнако такого рода «внутрисемейная оппозиџия» оказывается эффективна мишь на фоне внутреннего кризиса патриархата. В этом контексте примечательно следующее интервью": "Мои друзья и знакомьле бсе говорят, ито я женился ради гражданства на русской девушке. На самом деле я встретил девушку, обшался, и мьг решили поженится. На девушке своей начии я не женился, потому что мне не нравятся обичаи, которие биъаюот у нас при женитьбе. Зәесь, б России, попроше бьлл жениться, пошел, расписался и все. У нас обичаи женитьбь начиональньг, к исламу вообще никакого отношения не именот. То, как там выгают замуж, мне не нравится. И когда мои сестрь, племянники рассказьъают мне, как там проили свадьбь, я начинаю раздражаться и прошу мне этого не рассказывать. Там очень сложно жениться, много этапов нужно пройти. Съатовстьо и т.Ә., и нужно очень много денег, чтобь заплатить кальм, подарить всем дорогие подарки, сьграть съадьбу. Это все усложняет молодьим людям создать семью. Это скорее всего меня подтолкнуло жениться на русской девуике. И, конечно же, она мне понрабилась, мне захотелось создать семью с нейо.

Респондент не скрывает обиды на соотечественников, упрекающих его в браке по расчету, и субъективно прав. Но в определенном смысле расчет за его решением действительно стоит. Аля него брак стал символическим жестом частичной смены культурной традиции.

Здесь следует обратить внимание на высказывание «обычаи женитьбы национальные, к исламу вообще никакого отношения не имеют». Надо полагать, респонденту известны общедоступные сведения о формах приспособления ислама к условиям ареалов распространения. В Средней Азии исламская культура оказалась дополнена адатом, традиџионными нормами соџиальных взаимодействий, сложившимися в этом регионе на протяжении тысячелетий. Подобные процессы происходили с будАизмом в Центральной Азии, христианством - в европейских странах (вкАючая Восточную Европу), вобравшим в себя местные культы и обычаи вплоть до превращения старых богов в христианских святых. Исламизаџия, однако, как и христианизация - одна из форм глобализации. Респондент пытается доказать, прежкде всего самому

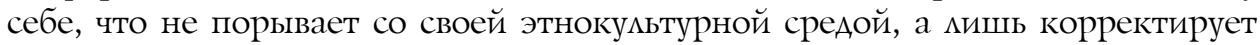
ее характеристики.

* Здесь и далее приводятся материалы авторского эмпирического исследования, осуществленного осенью 2018 - весной 2019 гг. Проведены биографические интервью с представителями сообщества мигрантов из стран ислама в Россию, и русскими девушками, вступившими в межнациональные браки (орфография и стилистика сохранены). 
На данный момент, однако, исламский мир остается зоной жесткого следования нормам патриархата. «Мне помогло то, ито я билл ей авторитетом в религии, и, конечно же, ее юньй возраст. В российском обществе принято, что жена является главной В семье, решает все вопрось. Муж только виполняет определенние требования, указь. Это то, ито неприемлемо для нас 8 наших семьях. Была у нас 6 начале конкурениия за лидерство $а$ семье, ну а потом это прошло. Я со сьоей сторонь проявлял терпение и понимание, потому что понимал, что человек воспитьгвался в другой культуре. Поэтому я от себя всегда требовал прояһлять терпение, слуиать до кониа и правильно, мудро принимать решение для того, итоби исправить сложивиуюся ситуачию. Нельзя решать вопрос сразу, как что-то случилось, нужно подождать и потом путем диалога обгяснения, разбяснения испраВить сложивиуюся ситуацию», - рассказывает Р. Но он тоже оказывается не в состоянии объективно оџенивать ситуацию в российских семьях. В его понимании семьи без главы быть не может. Если в России эту роль не выполняет мужчина, значит, она принадмежит женщине. При этом мудрость в его понимании состоит в том, чтобы чужАую традицию принять во внимание, а затем постепенно перебороть.

Разумеется, в конкретных случаях многое зависит от того, насколько посмедовательны объединившиеся в семью носители разных культурных традиџий в отстаивании привычных норм поведения. Собственно, здесь и проявмяются механизмы пограничных взаимодействий культур. С позиций М.М. Бахтина, большинство подобных взаимодействий следует рассматривать как негативно влияющие на культурную самоидентификацию [4]. В такой парадигме диалог культур служит необходимым условием саморефлексии каждой из них. «М.М. Бахтин пришел к теории “Аиалога культур” по мере анализа проблемы “Аругого”, рассматривая специфику художественного эстетического отношения через произведения культуры», - утверждает Н.А. Чумакоменко [5, с. 195] .

Только сопоставцяя собственную картину мира с иной, мюди могут опреАелить могику построения этой картины. «Важнейшая особенность, с которой М. Бахтин начинает характеристику диалога у Аостоевского, закмючается в том, что герои его произведений всегда обращены друг к Аругу и потому человек в диалоге всегда есть субъект обращения» [6], «о нем нельзя говорить, - можно мишь обращаться к нему» [4, с. 293] .

В реальных межккультурных взаимодействиях на первый план выходят, как правимо, прагматические интересы общностей. На протяжении всей чемовеческой истории эти интересы отстаивались чаше всего силовыми методами, что в культурном пространстве означало транскультураџию, сегрегаџию, геноциА. В тех случаях, когАа одной общности не уАается полностью поАчинить Аругую, наблюдается аккультурация [7], или ассимимяџия [8] (частичная, изредка полная, односторонняя или в виде культурного смешения), или интеграция [9]. Обычно выдемяют смедующие ее формы: конфигурационную (тематическую), стилистическую, цогическую, коннективную (на уровне непосредственной взаимосвязи составных частей культур при непосредственных контактах), функщиональную, регулятивную. 
На уровне семьи происходит обытовление межккультурных взаимодействий. Респондент-женшина рассказывает: «...но во многих других бъгтовигх моментах мне удалось его поменять. У нас долгой проблемой бъло то, ито он никогда не вьгкидивал мусор. У них это чисто женские дела. Так как я чертежник по профессии, у меня Всегда много бумажного мусора. И, когда я вихожу из дома, у мена всегда руки занятог кучей чертежей. И я ему говорю: "Ну, то идешь на улииу, возьми, пожалуйста, с собой по пути мусор, я не могу каждое утро таскать". Сначала он говорил: "Это твоя работа", но потом я ему обгяснила, ито это его работа тоже, и я не одна дома мусорю. И он начал бьгносить мусор. Если он покушал, то он никогда не моет за собой посуду, даже в мойку не может убрать. Просто он привиг, ито это женские обязанности. У них мама полностью о них заботится. Женшинь там не работают, а только следят за домашним уютом. Я обгяснила, что я не мама и не могу весь день ходить и подбирать за тобой все. В дальнейшем, кстати, он полюбил русские сериаль, начал понимать русский юомор».

В этом кейсе конфмикт Авух цивилизаџий происходит на уровне эмементарных взаимодействий. В странах арабского мира сохраняется разделение труда в весьма архаических формах, доминирование мужчин в обществе базируется на практически полном, как и полтора тысячелетия назаА, исключении женщины из сферы общественного производства. Парадокс, однако, заключается в том, что, оказавшись в России, араб попадает в ситуацию, когда занятость женшин «мужскими делами» явмяется естественной, общеочевидной, но и его собственное поведение воспринимается как адекватное не Аля мужкчины, а для инфантильного «маменькиного сыночка». Русская жена и воспринимает его в какой-то мере как избалованного ребенка, которого надо приучать «убирать за собой». Отнюдь не случайным представцяется в этом контексте и кажущийся на первый взгляд инородным пассаж о сериалах. Респондент осознанно объединяет в единый комплекс проџессы культурной ассимицяџии. Муж ее включается в принимающую культуру на поведенческом уровне, паралмельно принимая и сложившиеся в ней ценности.

Аналогичный проџесс, но противоположной направленности, описывает Аругая респондент: «У нас в русских семья все равно существует равноправие между мужем и женой. У них, у туркменов, принято, ито жена полностью подииняется мужу. Если муж что-то захотел, жена тут же должна пойти сделать, то что он сказал. Приготовить, убрать или что-то еще. У русских в такой ситуачии все равно начинатотся противоречия. Например, у меня муж никогда не моет посуду, а папа мой у нас дома моет посуду. То есть я привыкла, ито папа моет посуду. Аля мужа это било би чем-то нереальным, если бы он потел и помигл посуду. И, конечно же, больше под мужа подстроилась. Вьхходя замуж за нерусского парня, жене все равно придется, больше подстроиться под мужау.

Вопреки могике теоретических построений С. Хантингтона в описываемой реальности имеется не противоборство Авух цивилизаџий [10], а внутренняя борьба в каждой из них. Более архаичная культура, естественно,

76 Bulletin of the Volga Region Institute of Administration • 2019. Vol. 19. № 4 
более монолитна, поскольку в ней еще не произошло дифференџиаџии вариантов развития, накопмения потенциала изменчивости. Принадмежи наша респондент в определенной степени культуре модерна, она не приняла бы навязываемых ей норм. Найти экзотического жениха могма бы, но именно как выдемяющегося из общей массы, потенџиально обладающего неким человеческим капиталом, который можно использовать в привычной среде. ОАнако, насколько можно судить по интервью в целом, хотя родительская семья девушки жима отнюдь не по нормам домостроя, некоторые матентные представления о традиџионных ценностях в ней наблюдались. Они и реализовались сначала в выборе жениха, а затем и готовности принять в

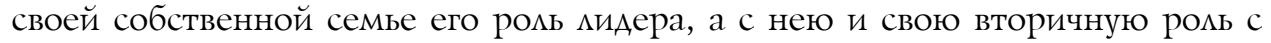
присушими ей обязанностями. Она знает, что может быть иначе, но ценность самостоятельности, права на принятие решений для нее не является определяющей.

Близким по смыслу представляется случай, описанный в следуюшем биографическом интервью: «У нас было много столкновений и непонимания 6 начале создания семьи. Например, В отношении к родителям, вот я скажу, ито В нашей русской культуре, $\boldsymbol{b}$ современной, родители не находятся на такой въготе, как, допустим, В кавказской культуре. Вот, например, муж мне сказал, какая у нас будет градачия. Сначала его родители, потом мои родственники, потом тьг. И вот это как бъ для меня бъло, с одной стороньи, шоком, почему я стою где-то 6 конче. Но со временем понимаешь правильность этого расположения и этой иерархии. ... На первьгх порах я не понимала, почему, если мои желания не совпадают с желаниями его родителей, почему они всегда отбрасьваются. Со временем только понимаешь, что это важно. И наверно, если би я тогда это поняла, меньше би всяких проблем било сейчас.

Я считаю, что мужиину очень трудно под себя подстроить, тем более кавказского. ...Моего мужа очень трудно перестроить, он крепко стоит на своих традициях. Конечно, он слегка ассимилировался В нашу культуру, например, какие-то правила поведения. И то, сейчас, когда он стал старше, он начинает говорить про свое и пьттается это сюда привнести. А в основном я подстраивалась и подстраиваюос до сих пор. Мне кажется, женшина-то и должна подстраиваться, мужиину ломать нельзя.

Но, естественно, я погталась поначалу его подстроить под себя. Тем более я била воспитана 6 такой семье, где мама била главньм человеком, то есть на ней строилась семья. И поэтому, естественно, ито вот этот пример был: "как мама скажет". Мьг не смотрели, как папа скажет, а как мама скажет, должно бьгть. У нас, например, бсе финансы хранились у мамит, а когда мьг начали жить вместе с мужем, у нас получилось так. Он же зарабатьгвал деньги и получалось, ито все деньги бьгли у него, и вот это тоже била такая трудность. И он тоже бил не готов к тому, итоби я распоряжалась деньгами. Он покупал еду и все, ито надо, и в приниие не отказивал мне. Но бот это, ито надо бьло идти просить, для меня было неприятно. Я хотела, чтобы деньги бьли у меня и чтобы он у меня их про- 
сил. Ему тоже пришлось перестраиваться, сейчас, например. Я знаю, ито у него есть какая-то сумма, и он мне дает какую-то сумму, и все равно мне отдает какие-то деньги на обиие расходь или если мне что-то нужно. Но вот на пербых порах проблемы такие бытовые были. Очень много било таких моментов, хорошо, ито у меня муж терпеливьй 6 этом плане».

Аанное описание характерно для кмассического патриархата. Аевушка входит в большую семью, где глава - не ее муж, а старший в роде, причем, как она сама понимает, есть некая «иерархия», согласно которой и строятся отношения. В действительности могика клановых сообшеств проста. Они существуют на стадии развития соџиума, когда институты Gesellschaft еще не получили развития. Э. Гидленс и У. Бек трактуют современные соџиумы как общества риска [11-13] (мир «институџионализированных среА рисков» [14], в котором «выгода от технико-экономического "прогресса" все больше оттесняется на задний план производством рисков» [12, с. 14] ), но в действительности уровень рисков в цивилизациях, предшествующих индустриальному обществу, бым много выше. Более основательной представляется позиџия Н. $\Lambda$ умана, полагающего, что традиционные общества сталкивались с риском в формате «неуверенности относительно будущего», «либо возможный ущерб рассматривается как следствие решения, т.е. вменяется решению. Тогда мы говорим о риске, именно о риске решения. Аибо же считается, что причины такового ущерба находятся вовне, т.е. вменяются окружающему миру. Тогда мы говорим об опасности» $[15$, с. 150]. Регулярные неурожаи, мелкие, но частые военные конфликты, несовершенство технологий в сумме делали шансы на выживание модели нуклеарной семьи минимальными, одинокая женщина таких шансов не имела вовсе.

Большая семья была инструментом перераспределения ресурсов, выполняя по сути функции хедж-фонда. Разумеется, при этом приходилось жертвовать индивидуальным развитием. Речь идет отнюдь не только о свободе выбора.

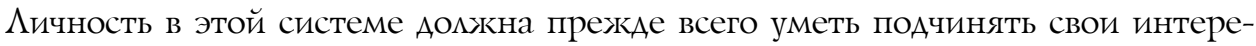
сы интересам клана. В Аолгосрочной перспективе это означает торможение развития, циклический характер изменений. Именно поэтому клановые общности на Алительной дистанџии проигрывают, как это описано, например, в романтизированной форме В. Скоттом или Р.А. Стивенсоном применительно к судьбе горџев Шотландии. ОАнако действительное разрушение клановых структур происходит мишь при полной интеграции их в общества индустриального типа. На Северном Кавказе эти процессы никак нельзя считать завершенными.

Как полагает И.В. Боровкова, «традиционный образ мужчины и образ “метросексуала” выражают размичные ценностные ориентации... Несмотря на его новизну, Аанный образ уже создает новые гендерные проблемы в обществе. Традиџионный образ мужчины, укоренившийся в ментальности русской культуры, входит в противоречие с теми образами, которые рекламирует субкультура глянца» [16]. Такого рода обобщение преАставляется слишком поспешным.

Рефлексия социальных аспектов мотиваџии вступления в брак присутству-

78 Bulletin of the Volga Region Institute of Administration • 2019. Vol. 19. № 4 
ет в следующем интервью: «...nросто понравился человек, не задумьгвалась особо о его начиональности, на тот момент ничего не знала об особенностях его менталитета, не пьталась узнавать, как там било у них. Стереотип бьл, считала нерусских мужиин (преимущественно кавказцев) лучше русских, более мужественными что ли...». В этом случае наблюдается не столько признание достоинств иной культуры, сколько критическое отношение к собственной сощиальной общности. При сравнении с соотечественниками мигранты идеализируются.

Об инфантилизме мужчин, впрочем, говорят и пишут не только в России, но и в европейских странах, США. Во многом такого рода оџенки источником имеют суждения женщин, ориентированных на модеми семьи, близкие к традиционным, со смешенным в сторону мужчины вектором ответственности, прежде всего за имущественное благосостояние.

В конџе 2018 - начале 2019 г. одной из наиболее популярных тем обсуждения на YouTube и ряде Аругих площадок стали претензии девушек к уровню доходов их партнеров или мужей: «Авести тысяч хотя бы, это минимум», - говорит симпатичная девушка на камеру (ролик собрал к апрелю 2019 г. 837349 просмотров) [17]; «пятьдесят тысяч рубкей в месяџ - это катастрофа», - утвержАают три девушки [18]; «ну, сто тысяч хотя бы» [19] ; «если нет базы какой-то, как можно строить семью, отношения начинать?» [20].

МежАу тем аналогичные уличные опросы демонстрировали обратное: пятьАесят тысяч рублей в месяџ, причем в Москве, - норма для обычных мюдей; «живут и на тридџать» [21]. В провинџии такие доходы преАставляются высокими. В Саратовской области в 2017 г., по оџенке Росстата, средняя заработная плата едва превысила 22 тыс. рублей, в 2018 г. - 27 тыс. рублей, что вызвало удивление жителей области [22]. Таким образом, выбор в пользу иностранцев осуществмяется на фоне очевидного несоответствия статуса большинства соотечественников запросам женщин.

Образ «метросексуала» входит в противоречие с традиционными схемами и английской, и итальянской, и китайской, и японской, и «даже» французской, культуры. Аюбая инноваџия (безотносительно к оџенке ее значимости, адаптивности, продуктивности), естественно, не может находиться в согласии с традиџией. Говорить о наџиональной специфике здесь некорректно.

Аля народной культуры (без каких-либо национальных различий), что наиболее выраженно зафиксировано применительно к периоду XVIII-XIX стометий, характерно иронически-негативное восприятие мужчины типа «петиметра», щегомя, бездельника, который может показаться некоторым аналогом метросексуала. Создается имлюзия, что в этом плане действительно можно рассужАать о некотором продолжении традиџии в разного рода публицистических выступцениях по повоАУ «чужАости» глянџа народной куцьтуре. ОАнако «петиметр» Аля негативных восприятий народной массы XVIII-XIX вв. был не основной, а самой доступной мишенью. К жандармам отнюдь не питали Аюбви, но смеяться наА ними опасались в большей степени, потому что это могло иметь нежелательные послеАствия. 
Что касается собственно гендерных отношений, метросексуал может вызывать негативное восприятие в той мере, в какой близок типу пикапера, по сути сутенера, пытающегося паразитировать на женщинах. Разумеется, Аля определенной части женщин, сохраняющих патриархальный тип сознания, он противопоставлен «положительному» мужчине, хорошему семьянину, подчиняться которому необходимо, потому что он «обеспечивает» женщину. Вместе с тем подобная позиция означает отказ от самостоятельности, и в этом плане Амя феминистского сознания в образе метросексуала не Аолжно быть негативного содержания.

Инаковость сама по себе может привлекать, создавая романтический интерес: «... так получилось, ито я познакомилась с парнем-сирийцем, которьй приехал учиться 8 Россию. Не било такого, что я спеииально искала мужа араба. И, если смотреть среди местньхх мусульман - например, проживаюших на Кабказе, - мне кажется, что арабь более ближе к русским, чем кабказць», - рассказывает М.

Имеются также случаи осознанного выбора женихов из мигрантских сообществ: «Страха не било вьхходить замуж за человека с другой странь и другой наииональности. Потому что я до знакомства с мужем приняла ислам, и для меня главное было бигити замуж за мусульманиная. В данном случае речь идет о смене соџиокультурной ориентации. По сути, респондент избирает один из возможных способов такого переключения, связанного не с Аичным выбором в пользу конкретного носителя той или иной культурной традиџии, а с выбором самой традиџии. ОАнако такой вариант распространенным не является. Он, как правило, реален для девушек, родившихся в семьях, ориентированных на ислам, и в крайне редких случаях - в ситуациях индивидуального решения в пользу ислама, сделанного на том или ином социокультурном фоне.

Пересмотр модемей семьи в российском социуме идет последние три стометия в том же направлении, что и в европейских странах, но осложнен противоречиями проџессов модернизации общества в целом. Россия пережима революџионный слом общественно-политического устройства и системы соџиально-экономических отношений, прошла через соџиалистический эксперимент, сопряженный с жесткой борьбой разАичных представлений о путях перехода к соџиализму, осуществила возврат к рыночным отношениям. Государственная политика в отношении семьи неоднократно пересматривалась, при этом вполне естественно появление конкурирующих представлений об устройстве семьи, мужских и женских роцях в ней.

В Аанном исследовании внимание сосредоточено на одном из аспектов конструирования женщинами ролей своих партнеров по браку, которое носит преимущественно практический характер, поскольку теоретический план экспликации интересов женщин связан в большей степени с феминизмом, когАа брачные отношения артикулируются крайне слабо. В практиках, ориентированных на традищионные ценности, женщины чаще всего выбирают мужчин, преАставляющих культуры традищионного типа. При этом, однако, открытым остается вопрос о гарантиях собственно российской идентичности. 


\section{Библиографический список}

1. Синельников А.Б. Кризис брачно-семейных и межпоколенных отношений и приоритетные направления демографической политики в России: дис. ... д-ра социол. наук. М., 2015.

2. Булгакова C.A. Кризис семьи и традиционных устоев в современном обществе // Инновационная наука. 2016. № 5-1 (17). С. 215-217.

3. Джабер X.М.A. Семейные ценности в арабской культуре // Психология образования в поликультурном пространстве. 2016. № 33 (1). С. 24-28.

4. Бахтин М.М. Проблемы поэтики Достоевского. М., 2017.

5. Чумаколенко Н.А. Теория «диалога культур» М.М. Бахтина - В.С. Библера и развитие медиаобразования в художественно-эстетическом образовании и воспитании школьников // Теория и практика общественного развития. 2013. № 1. С. 194-196.

6. Дьяконов Г.В. Концепция диалога М.М. Бахтина - основа экзистенциально-онтологической психологии // Диалог культур XXI. URL: http://www.culturedialogue.org/drupal/ru/node/847

7. Павловская O.A. Аккультурация: проблемы национального самосознания // Россия и Запад: диалог культур. URL: http://regionalstudies.ru/journal/homejornal/rubric/2012-11-02-22-0327/335--1-r.html

8. Тотров Р. Межкультурные отношения: мировоззрение и адаптация. Из опыта американских исследований. URL: http://www.e-хеcutive.ru/community/articles/631218/

9. Беляева E.E. Культурная интеграция как основная стратегия культурной политики Европейского союза: дис. ... канд. культурологии. М., 2011.

10. Хантингтон С. Столкновение цивилизаций. М., 2003.

11. Giddens A. Modernity and Self-Identity: Self and Society in the Late Modern Age. Stanford, Calif:: Stanford University Press, 1991.

12. Бек У. Общество риска. На пути к другому модерну. М., 2000.

13. Яницкий О.Н. Социология риска: ключевые идеи // Мир России. 2003. № 1.

14. Лебедева Л.Г. [и др.]. Концепции общества риска в социологическом дискурсе // Вестник Самарского муниципального института управления. 2014. № 2. С. 129-137.

15. Луман Н. Понятие риска // Альманах THESIS. 1994. № 5.

16. Боровкова И.В. Изменение социальных ролей мужчин и женщин как феномен в современной культуре // Молодой ученый. 2012. № 4. С. 512-514.

17. Сколько должен зарабатывать мужчина? Опрос девушек. Средняя зарплата в Москве для жизни. URL: https://www.youtube.com/watch?

18. Сколько должен зарабатывать мужчина в Москве? Красавицы - почти даром! Реакция. URL: https://www.youtube.com/watch?v=bFKE-U0I4Kc

19. Сколько должен зарабатывать мужчина? Реальный опрос девушек Москвы. URL: https://www.youtube.com/watch?v=u1GZV99Lh8k

20. Сколько должен зарабатывать мужчина (опрос содержанок). URL: https://www.youtube. $\mathrm{com} /$ watch? $\mathrm{v}=\mathrm{kqlB} 9 \mathrm{mibOgs}$

21. Сколько должен зарабатывать мужчина? Средняя зарплата в Москве в спальных районах. URL: https://www.youtube.com/watch?v=NwxJfk6N86g

22. Саратовцы о средней зарплате в регионе по данным Росстата. URL: Rush Word YouTube Published on Jul 30, 2018 